\title{
Effect of Acute Warm Water Swim Stress on Antioxidant Levels in Swiss Albino Rats
}

\author{
B.A.Madhuri ${ }^{1}$, Rajeswar Reddy ${ }^{2}$ \\ ${ }^{1}$ Assistant Professor, ${ }^{2}$ Associate Professor, Department of Physiology, RVM Institute of Medical Sciences and \\ Research Center, Mulugu, Laxmakkapally, Telangana
}

\begin{abstract}
Background: Heat stress affects both physical and mental tasks. Imbalance in maintenance of temperature leads to oxidative stress and damage to the body systems. Aim: To evaluate the effect of acute warm water swim stress on antioxidant status changes in albino rats. Materials and Methods: The present study was conducted in the Department of Physiology, Meenakshi medical College\& Research Institute, Chennai. Twenty male albino rats were randomly divided in to two groups, control group and experimental group. Experimental group of rats were exposed to warm water swim stress at $40^{\circ} \mathrm{c}$ for duration of $15 \mathrm{~min}$ of continuous single exposure. The antioxidant status namely enzyme activity (LPO,CAT, SOD \& GPx) and non-enzyme activity (Vitamin C \& Vitamin E) were estimated as per standard procedures. Results: There was a significant $(\mathrm{P}<0.001)$ increase in Lipid peroxidation and was significantly $(\mathrm{P}<0.001)$ decrease in enzyme activity (SOD, CAT, \& GPx) and non- enzyme activity (Vitamin C \& Vitamin E) when compared with their normal controls. Conclusion: The changes in antioxidant estimation helps in developing a new approach in understanding the changes in the body under acute exposure to heat water swim stress which is mainly responsible for pathophysiological changes and to know the thermoregulatory activities of the mammals.
\end{abstract}

Key words: Antioxidant, stress, warm water

\section{Introduction}

Stress is a universal phenomenon and induces physiological and behavioral changes in an organism to maintain the homeostasis ${ }^{1}$. Acute stress exposure has detrimental effect on several cell functions. Swimming is not always a simple exercise stress, because emotional factors are difficult to be eliminated ${ }^{2}$. Swimming in small laboratory animals has been widely used for studying the physiological changes and the capacity of the organism in response to stress ${ }^{3}$. Maintenance of water temperature is another important factor contributing to swim stress. By varying the water temperature and found that rats

\section{Corresponding Author:}

Dr. B.A. Madhuri

Assistant Professor, Department of Physiology RVM Institute of Medical Sciences and Research Center, Mulugu, Laxmakkapally, Telangana-

Email: physio.rvm@gmail.com could survive as long as 80 hours in lukewarm water ${ }^{4}$. Increasing or decreasing the water temperature above or below this point influences the overall behavior of the animal and changes the involvement of glucocorticoids ${ }^{5}$. Free radicals may be either oxygen derived (ROS, reactive oxygen species) or nitrogen derived (RNS, reactive nitrogen species). Antioxidant act as radical scavengers, and convert the radicals to less reactive species. The antioxidative system includes both enzymatic and non-enzymatic systems ${ }^{6,7}$. We intend to explore the physiological changes that can happen during heat stress and biomarker involved in this type of specific stress. The present study was undertaken to evaluate the effect of acute heat water swim stress on antioxidant status changes in albino rats.

\section{Materials and Methods}

Twenty Adult male albino rats weighing about 150-180grams were used for the study. The study was conducted in Department of Physiology, Meenakshi 
medical College\& Research Institute, Chennai. The experimental rats were housed in polypropylene cages and maintained under standard conditions. Standard pelletized feed and tap water were provided ad libitum. The rats were randomly divided in to two groups, Group-I (Control) and experimental group. The experimental group rats were exposed to heat water swim stress at $40^{\circ} \mathrm{C}$ for duration of $15 \mathrm{~min}$ between 09.00AM to11.00AM for one day. Blood samples are collected from jugular vein after heat water swim stress for antioxidant estimation ${ }^{8}$. The Lipid peroxidation (LPO), enzymatic antioxidant estimation like Superoxide dismutase (SOD), Glutathione peroxidase (GPx), and non-enzymatic antioxidants like Vitamin C, Vitamin E are estimated. The Institutional
Animal Ethical Committee approved the study.

\section{Results}

There was a significant increase in lipid peroxidation (Table-1) with decrease in antioxidant enzymes like superoxide dismutase (SOD), glutathione peroxidase (GPx) and catalase (CAT) in heat water swim stress when compared to control group animals (Table-2). The non-enzymatic antioxidants vitamin $\mathrm{C}$ and $\mathrm{E}$ are significantly decreased in heat water swim stress group when compared to control group (Table-3). All the parameters were recorded and analyzed by using student's t- test and considered $\mathrm{P}<0.05$ as statistically significant.

Table 1: Lipid peroxidation (LPO)

\begin{tabular}{|l|l|l|}
\hline LPO (nmoles of MDA/min/mg/ptn) & Mean+Sd & P-value \\
\hline Controls & $84.98+3.25$ & $<0.05^{*}$ \\
\hline $\begin{array}{l}\text { Hot water } \\
\text { swim stress }\end{array}$ & $111.66+7.08$ & \\
\hline
\end{tabular}

Table 2: Enzymatic Antioxidants: SOD, CAT and GPX

\begin{tabular}{|l|l|l|}
\hline Enzymatic & Mean+Sd & P-value \\
\hline SOD(min/mg/ptn) Control & $5.68+0.22$ & $<0.05^{*}$ \\
\hline Heat water swim stress & $2.60+0.75$ & $<0.05^{*}$ \\
\hline CAT (min/mg/ptn) Control & $3.71+0.21$ & $<0.05^{*}$ \\
\hline Heat water swim stress & $2.34+0.36$ & $<0.05^{*}$ \\
\hline GPx (min/mg/ptn) Controls & $6.40+0.28$ & $<0.05^{*}$ \\
\hline Heat water swim stress & $4.56+0.62$ & $<0.05^{*}$ \\
\hline
\end{tabular}

Table 3: Non-Enzymatic Antioxidants: VIT C and VIT E

\begin{tabular}{|c|c|c|}
\hline Non-Enzymatic & Mean + Sd & P-value \\
\hline $\begin{array}{l}\text { VIT C ( } \mu / \mathrm{mg} \text { ptn }) \\
\text { Controls }\end{array}$ & $2.33+0.28$ & \multirow[b]{2}{*}{$<0.05^{*}$} \\
\hline $\begin{array}{l}\text { Hot water } \\
\text { swim stress }\end{array}$ & $1.25+0.62$ & \\
\hline $\begin{array}{l}\text { VIT E } \mu / \mathrm{mg} \text { ptn } \\
\text { Controls }\end{array}$ & $2.41+0.05$ & \multirow[b]{2}{*}{$<0.05^{*}$} \\
\hline $\begin{array}{l}\text { Hot water } \\
\text { swim stress }\end{array}$ & $1.24+0.62$ & \\
\hline
\end{tabular}




\section{Discussion}

There has been limited research on the effects of acute heat water swim stress. The effect of acute exposure to heat water swim stress on antioxidant status in rats has been intensively investigated. The present study indicates that the acute exposure to heat water swim stress for $15 \mathrm{~min}$ at $38^{\circ} \mathrm{C}$ in a single day showed significant increase in lipid peroxidation. The increased level of lipid peroxidation is the evidence most frequently cited in support of the involvement of oxidative stress in tissues. It is a molecular mechanism of cell injury leading yield a wide range of cytotoxic products, most of which are aldehydes, malondialdehyde ${ }^{9}$. The data suggest that there is the activation of free radical precursors in all investigated tissues. Antioxidants both enzymatic (superoxide dismutase, glutathione peroxidase \& catalase) and nonenzymatic (vitamins $\mathrm{C}$ and $\mathrm{E}$ ) provide necessary defense against oxidative stress generated due to high ambient temperature ${ }^{10}$. The concentration of free radicals during normal oxygen metabolism is controlled by various antioxidants and a balance exists between pro-oxidant and antioxidant processes. Free radicals damage biomembranes, reflected by increased lipid peroxidation, thereby compromising cell integrity and function due to reduced antioxidants. Superoxide dismutase (SOD) in conjugation with catalase and glutathione peroxidase (GPx) scavenges both intracellular and extracellular superoxide radicals and prevents lipid peroxidation ${ }^{11}$.Reduced glutathione, glutathione peroxidase and superoxide dismutase form a part of the antioxidant defense systems produced by the body to protect the cellular constituents from the damages caused by ROS. Ascorbic acid is an important antioxidant in plasma and acts in tissues, involving ROS in aqueous phase ${ }^{12}$. It is a major antioxidant since, mice lack of L- gulunolactose oxidase, a gene responsible for synthesis of ascorbic acid leads to decreased plasma antioxidant capability, suggesting that these animals may be susceptible to increased level of oxidative stress in the brain. In the brain, ascorbic acid has a dual effectat low concentrations it promotes lipid peroxidation and at higher concentrations it acts as an antioxidant ${ }^{13}$.It is also an anti-stress factor ${ }^{13,14}$. Our study also concurs with similar anti-stress effect of ascorbic acid. Vitamin $\mathrm{E}$ is the primary lipid soluble antioxidant, and plays an important role in scavenging of free oxygen radicals and stabilizes the cell membranes in maintaining its permeability ${ }^{15}$.It is bound to the protein complexes in the inner mitochondrial membranes and may affect oxidative changes which occur in organelle ${ }^{16}$. In our study, vitamin E has definite role in counteracting stressful situations in animals and it concurs with our study. Alpha-Tocopherol has a peripheral anti-inflammatory effect and this could be related to inhibition of scavenging of free radicals developed due to stress. Vitamin E increases the level of prostaglandins which was decreased during stress which may enhance the exploratory and loco motor activity $^{8}$. Apha-Tocopherol inhibits the activity of nitric oxide. This action was done by inhibiting the gene responsible for activation of the transcription factor $\mathrm{NF}-\kappa \mathrm{KB}$ by nitric oxide ${ }^{17}$. Vitamin $\mathrm{C}$ and $\mathrm{E}$ cause the inhibition of peroxidation, mopping up of free radicals and disorganization and breakage of peroxidation chain reactions by an inhibition of glutathione peroxidase and proteinkinase, resulting in blockade of oxidative mechanism ${ }^{18}$. To conclude, antioxidants like vitamin $\mathrm{E}$ and ascorbic acid act synergically, preventing lipid peroxidation and cell destruction.

\section{Conclusion}

The exposures to heat water swim stress leading to oxidative damage and generation of free radicals. The human antioxidant protection system involves a variety of components both endogenous and exogenous functions interactively and synergistically to neutralize free radicals caused by reactive oxygen species. These studies support accumulating evidence for brain activity to be dynamically regulated by immune system factors.

\section{References}

1. Nayanatara A K, Nagaraja H S, and Anupama B K. The effect of repeated swimming stress on organ weights and lipid peroxidation in rats. Thai journal of physiological sciences.2005; 18:3-9.

2. Kramer K, Dijkstra H, and Bast A. Control of physical exercise of rats in a swimming basin. Physiol Behav.1993; 53: 271-276.

3. GreenenD, Buttrick P, and Scheuer J. Cardiovascular and hormonal responses to swimming and running in the rat. J Appl Physio.1988; 65: 116-123.

4. Tan N, Morimoto K, Sugiura T, Morimoto A, and Murakami N. Effects of running training on the 
blood glucose and lactate in rats during rest and swimming. Physiol Behav.1992; 51: 927-931.

5. Richter C P. On the phenomenon of sudden death in animals and man. Psychosom Med.1957; 9: 191198.

6. Ames B.N, Shigenega M.K, Hagen T.M. Oxidants and the degenerative diseases of ageing" Proc Nati Acad Sci.1993; 90: 7915-22.

7. Shenoy R, Shirwaikar A, "Anti-inflammatory and free radical scavenging studies of Hyptis suaveolens (labiatae). Indian drugs.2002; 39: 574 -577 .

8. Ige SF, Akhigbe RE, Omobowale GK, Azeez OM, Ajao FO, Saka WA and Oyekunle OS: Immunomodulatory effect of warm water swim stress in adult female Sprague Dawley rats. Research Journal of Immunology 2011; 4(1): 2530 .

9. Gutteridge JMC. Lipid peroxidation and antioxidants as biomarkers of tissue damage. Clin Chem.1995; 41(12):1819-28.

10. Astrand,P.O. and Rodahl,K.(1970) Text book of work physiology ,McGraw-Hill Book company,New York,USA.

11. Halliwell B, Gutteridge JMC. Oxygen radicals and the nervous system. Trends Neurosci. 1985;8:22-6.
12. Frei B, England L, Ames BN. Ascorbate is an outstanding antioxidant in human blood plasma. Proc Natl Acad Sci.1989;86:6377-81.

13. Chinoy NJ, Sharma M, Michael M. Beneficial effects of ascorbic acid and calcium on reversal of fluoride toxicity in male rats. Fluoride 1993;26:4556.

14. Chinoy NJ. Metabolic significances of ascorbic acid in animal and human tissues.J Animal Morphol Physiol.1978:68-75.

15. Shaikh Z.A., Vu T.T. and Zaman K. Oxidative Stress as a Mechanism of Chronic Cadmium-Induced Hepatotoxicity and Renal Toxicity and Protection by Antioxidants, Toxicol. Appl. Pharmacol.1999; 154: 256-263.

16. Ernster L., Fosmark P. and Nordenbrand K. The mode of action of lipid-soluble antioxidants in biological membranes. Relationship between the effects of ubiquinol and vitamin $\mathrm{E}$ as inhibitors of lipid peroxidation in submitochondrial particles, J. Nutr. Sci. Vitaminol. Spec.1992: 548-551.

17. Frei B, England L, Ames BN. Ascorbate is an outstanding antioxidant in human blood plasma. Proc Natl Acad Sci.1989;86:6377-81.

18. Murray,K.M. Granner,D.K.Mayer,P.A. and Rodwell,V.W. Text book of Harpers biochemistry $25^{\text {th }}$ edition. $2000 ; 8: 83-85,130-136$. 